\title{
DISTRIBUIÇÃO NO TEMPO GEOLÓGICO DOS PRINCIPAIS DEPÓSITOS MINERAIS BRASILEIROS: 2. ÉPOCAS METALOGENÉTICAS
}

\author{
JOÃO C. BIONDI*
}

\begin{abstract}
TIME DISTRIBUTION OF THE MAIN BRAZILIAN MINERAL DEPOSITS: 2. METALOGENIC EPOCHS The metalogenic epochs of the main mineral deposit groups were defmed with base on the ore's ages of the 194 main brazilian mineral deposits. Mineral deposits are rare on epochs that: (1) preced the beginning of juvenile accretion peak periods and/or (2) of cooling of rocks formed during each of the main brazilian thermo-tectonic events. Deposits are more frequent on epochs that are coincident or immediatly younger than these peak periods. The most important metalogenic epoch, with about 30\% of the selected deposits, is between 50 Ma and the Recent, and corresponds to the formation of supergenic and/or residual and placer deposits. Brazilian's volcanogenic (VHMS), Mississippi Valley (MVT) and mesothermal gold-lode deposits have discordant ages as compared with their equivalents in other countries, while deposits believed to be SEDEX have concordant ages. With the exception of Urucum, the primary iron and manganese ores of brazilian deposits are Archean. Primary tin deposits from Amazonas, Amapá and Goiás States cluster between 1500 and 2300 Ma. Tin deposits from Rondônia and Mato Grosso are more recen and most formed between 1000 and $1600 \mathrm{Ma}$, in sequence with the other groups of tin deposits. Uranium deposits vary on genetic model and ages, due to the mobility of the element in ali geologic environments. Most part of brazilian deposits of phophate, titanium, niobium, Rare Earths, diamond in kimberlites and of amethist formed during the Mesozoic, and arte genetically related to the alkaline and basaltic magmatism that affected the brazilian territory in this period. Gemstone (tourmaline and acquamarine), tale and magnesit deposits are more frequent in the Brasiliano period. Gipsite, silvite and barite occur in Senonian to Aptian evaporites.
\end{abstract}

Keywords: Brazilian mineral deposits, metallogenetic epochs, time distribution of mineral deposits.

RESUMO A partir das idades das mineralizações dos 194 depósitos minerais brasileiros mais importantes, foram determinadas épocas metalogenéticas dos principais grupos de depósitos. Frequências menores de depósitos parecem ocorrer em épocas: (1) que antecedem o início dos períodos de maior atividade de acresção de material juvenil e/ou; (2) de resfriamento das rochas formadas em cada um dos principais eventos termo-tectônicos brasileiros. As maiores frequências ocorrem em épocas coincidentes ou imediatamente posteriores a esses períodos. A época metalogenética mais importante, que contém cerca de 30\% dos depósitos selecionados, situa-se desde 50 Ma até o Recente, na qual estão os depósitos supergênicos e/ou residuais e em aluviões. Os depósitos vulcanogênicos (VHMS), os do tipo Mississipi Valley (MVT) e os mesotermais com ouro têm idades geralmente discordantes com equivalentes de outros países, enquanto os depósitos considerados SEDEX em sua maioria têm idades coincidentes. Com a exceção de Urucum, a mineralização primária de ferro e de manganês dos depósitos brasileiros é Arqueana. Os depósitos primários de estanho do Ámazonas, do Amapá e de Goiás constituem grupos com idades entre 1500 e 2300 Ma. Os depósitos rondonianos e matogrossenses em sua maioria formaram-se no intervalo 1000-1600 Ma, imediatamente em sequência aos dos outros grupos. Os depósitos de urânio ocorrem em modelos variados com idades também muito variadas, consequentes da grande mobilidade desse elemento em todos os ambientes geológicos. A maioria dos depó'sitos de fosfato, titânio, nióbio, Terras Raras, diamantes em kimberlitos e de ametista são Mesozóicos, geneticamente relacionados ao magmatismo que afetou grande parte do território brasileiro naquela época. O Brasiliano é a época de maior frequência em depósitos de pedras preciosas (turmalina, água marinha) e de talco e magnesita. Gipsita, sil vita e barita estão em evaporitos com idades entre o Senoniano e o Aptiano.

Palavras-chaves: Depósitos minerais brasileiros, épocas metalogenéticas, distribuição no tempo dos depósitos minerais

INTRODUÇÃ̃O Na primeira parte desse trabalho (Biondi, nesse número) foi apresentado um banco de dados contendo 194 depósitos minerais brasileiros selecionados pelas suas importâncias económicas e/ou prospectivas. Esses depósitos serão agora agrupados e os diversos grupos situados no tempo conforme as idades das mineralizações.

As interpretações serão feitas a partir de histogramas cujos intervalos de frequência serão de $50 \mathrm{Ma}$. Assim, a categorizacão das idades das mineralizações em provável, possível e indicada feita anteriormente (Biondi, nesse número) terá esta precisão, considerando a possibilidade de uma dada idade estar efetivamente situada no intervalo de frequência de 50 Ma a partir do resultado da datação.

\section{DISTRIBUICÃO NO TEMPO DOS DEPÓSITOS MINERAIS} BRASILEIROS Histogramas de frequência Os histogramas que mostram a distribuição das idades dos depósitos minerais (Fig. 1 a 13) brasileiros foram construídos do seguinte modo:

1. O intervalo de frequência é constante em todos os histogramas, igual a $50 \mathrm{Ma}$.

2. Um depósito mineral cuja idade indicada na tabela de Biondi (nesse número) abrange um intervalo de tempo maior que 50 Ma teve sua idade computada em todos os intervalos de frequência abrangidos pelo seu intervalo de idade. Logo, quando o referido intervalo estiver na categoria possivel ou indicado, a frequência nesse intervalo não corresponde necessariamente ao número de depósitos cujas idades fazem parte desse intervalo, e sim ao número de depósitos cujas idades podem (existência da possibilidade) fazer parte desse intervalo.

3. Vários histogramas mostrarão a distribuição no tempo de depósitos minerais de outros países, permitindo a comparação com a distribuição dos depósitos brasileiros. Nesses histogramas geralmente serão mostrados, também, os intervalos de maior atividade de acresção de material crustal juvenil (idades Sm-Nd T(DM), em Biondi 1997 b, c, d, e Sato 1998), de cristalização (idades U-Pb e Pb-Pb) e de resfriamento (idades $\mathrm{Rb}-\mathrm{Sr}$ em rocha total e idades $\mathrm{K}-\mathrm{Ar}$ em hornblenda e biotita) dos principais eventos termo-tectônicos que afetaram o Brasil, conforme discutido por Biondi (1997 b, c, d;) e Sato (1998).

Distribuição no tempo dos depósitos minerais VISÃO GERAL A figura 1 é um histograma geral das idades dos 194 depósitos minerais mencionados na tabela de Biondi (nesse número), comparadas às épocas de maior atividade (pico) dos eventos termotectônicos brasileiros segundo Biondi (1997 a, b, c) e Sato 1998. Embora as idades distribuam-se por todas as épocas, desde há 3000 Ma, podem ser percebidas frequências menores, ou mesmo a ausência de depósitos, em épocas que antecedem o início da acresção de material crustal juvenil e/ou do resfriamento das rochas formadas em cada um dos principais eventos termo-tectônicos brasileiros. Essas épocas correspondem ao final do ciclo anterior, quando praticamente cessaram as atividades térmicas e tectônicas, não restando fenómenos energéticos capazes de gerar depósitos minerais primários (que não sejam gerados por fenómenos superficiais, químicos ou gravitacionais). Como exemplos (Fig. 1) podem ser citados o intervalo entre 2800 e $3000 \mathrm{Ma}$, que antecedeu o Jequié, o intervalo 2250-2500, antes do Trasamazônico, o intervalo 1300-1500, antes do Espinhaco-Rondoniano e o intervalo 650-800, antes do início da fase principal de cristalização/resfriamento das rochas do Brasiliano.

Os máximos de atividade de formação de depósitos coincidem ou sucedem imediatamente as principais épocas de cristalização/resfriamento de cada um desses eventos tectônicos maiores. Assim é para o intervalo 2650-2800 do Jequié, 1950-2150 do Transamazônico, 10001250 após o Espinhaço-Rondoniano e para o intervalo 450-700 do Brasiliano. Ao contrário dos finais desses ciclos, esses períodos devem corresponder às épocas de maior disponibilidade de energia, térmica e tectônica, na superficie da litosfera, o que facilitaria a formação dos depósitos minerais.

Nas épocas intermediárias, situadas entre os períodos de maior disponibilidade energética de cada ciclo tectônico, devem formar-se depósitos superficiais cujas géneses dependem de fenómenos químicos (precipitações/sedimentações químicas, concentrações supergênicas e/ou residuais, reações minerais intempéricas, etc.) e físicos (gradientes térmicos, gravidade, etc.) que independem ou não se correlacionam necessariamente com eventos termo-tectônicos. A distribuição das idades de todos esses grupos de depósitos serão discutidos a seguir.

DEPÓSITOS RESIDUAIS E SUPERGÊNICOS A figura 2 mostra a distribuição das idades dos principais depósitos supergênicos e/ou residuais brasileiros. Por serem depósitos superficiais, dificilmente depósitos antigos desse tipo foram preservados. Os depósitos de U(Au) 
da Formação Moeda (Quadrilátero Ferrífero) e de Au de Jacobina são paleoplacers preservados desde o Paleoproterozóico. O depósito de $\mathrm{Cu}(\mathrm{Ag})$ de Pedra Verde (Ceará) foi interpretado por Brizzi \& Roberto (1988) como produto de enriquecimento supergênico ocorrido há cerca de $1150 \mathrm{Ma}$ sobre filitos mineralizados. E o único depósito antigo relatado corno sendo desse tipo conhecido no país. Todos os outros são do Cretáceo ou posteriores.

Comparada com a figura 1, a figura 2 mostra que dos 194 depósitos brasileiros mais importantes, $57(\approx 30 \%)$ são supergênicos e/ou residuais e têm idades posteriores ao Eoceno. Os mais importantes depósitos desse grupo (Tabela de Biondi, nesse número) são os depósitos de níquel garnierítico (18), de bauxita (8), as concentrações residuais de $\mathrm{Ti}, \mathrm{Nb}$, apatita $(\mathrm{P})$ e elementos Terras Raras em carbonatitos (8) e as concentrações residuais/supergênicas de Mn (4), todos com idades entre o Eoceno e o Plioceno (Schobbenhaus \& Coelho 1986). Do Pleistoceno ao Recente formaram-se os pláceres a cassiterita (8), diamante (5) e ouro, entre outros.

As concentrações residuais/supergênicas, que formam o maior grupo de depósitos minerais brasileiros, parecem, nas regiões central e sudeste do Brasil, relacionadas geneticamente às superfícies de aplainamento Sul-Americana e Japi, ambas do Eoceno ao Oligoceno.
Na Amazônia, a superficie Velhas, (plio-pleitocênica), seria o controle maior (vários autores, in Schobbenhaus \& Coelho 1986, 1988, vide tabela) das bauxitas. Os depósitos em pláceres atuais formaram-se por erosão de depósitos primários ou remobilização de pláceres antigos, sobretudo durante as fases de soerguimento epirogênico que sucederam essas épocas de estabilidade.

DEPÓSITOS VULCANOGÊNICOS A figura 3 mostra a distribuição das idades dos principais depósitos vulcanogênicos brasileiros. Foram considerados: (1) os depósitos vulcanogênicos distais, com $\mathrm{Pb}, \mathrm{Zn}, \mathrm{Ag}$, ou exalativo-sedimentares (SEDEX), relacionados a vulcanismo ácido, (2) os depósitos distais com $\mathrm{Cu}, \mathrm{Zn}(\mathrm{Au})$, exalativo sedimentares (SEDEX) relacionados a vulcanismo básico ou tipo Besshi, (3) os depósitos proximais com $\mathrm{Cu}(\mathrm{Au})$, ou com sulfeto maciço tipo Abitibi. Embora sejam depósitos sedimentares químicos, e não vulcanogênicos, devido a relação espacial e genética que têm com os depósitos vulcanogênicos, também foram incluídas nesse histograma (4) os depósitos de Au em formações ferríferas bandadas (BIF) tipo Algoma em cherts e (5) os depósitos gigantes de $\mathrm{Fe}(\mathrm{Au})$ em formações ferrífera bandadas tipo Superior, como as do Quadrilátero Ferrífero (MG) e de Carajás (PA). Esse último tipo de formação ferrífera caracteriza

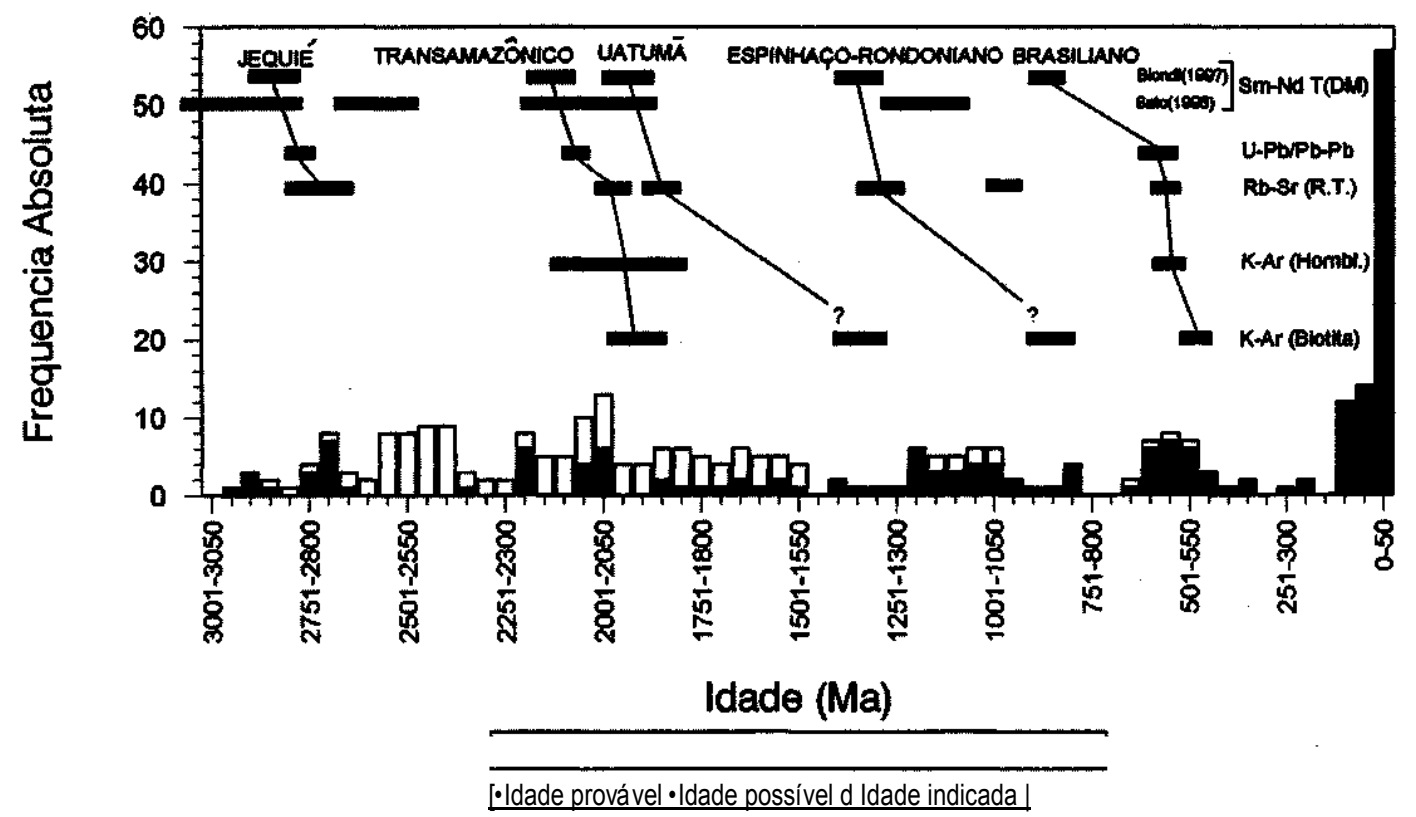

Figura l-Idades dos principais depósitos minerais brasileiros comparadas aos períodos de máxima atividade de acresção de material crustal juvenil (idades $\mathrm{Sm}-\mathrm{Nd} T(\mathrm{DM})$ ), de cristalização (idades $\mathrm{U}-\mathrm{Pb}$ e $\mathrm{Pb}-\mathrm{Pb}$ ) e de resfriamento (idades $\mathrm{Rb}-\mathrm{Sr}$ em rocha total e idades $\mathrm{K}$-Ar em hornblenda e biotita) dos principais eventos termo-tectônicos que afetaram o Brasil.

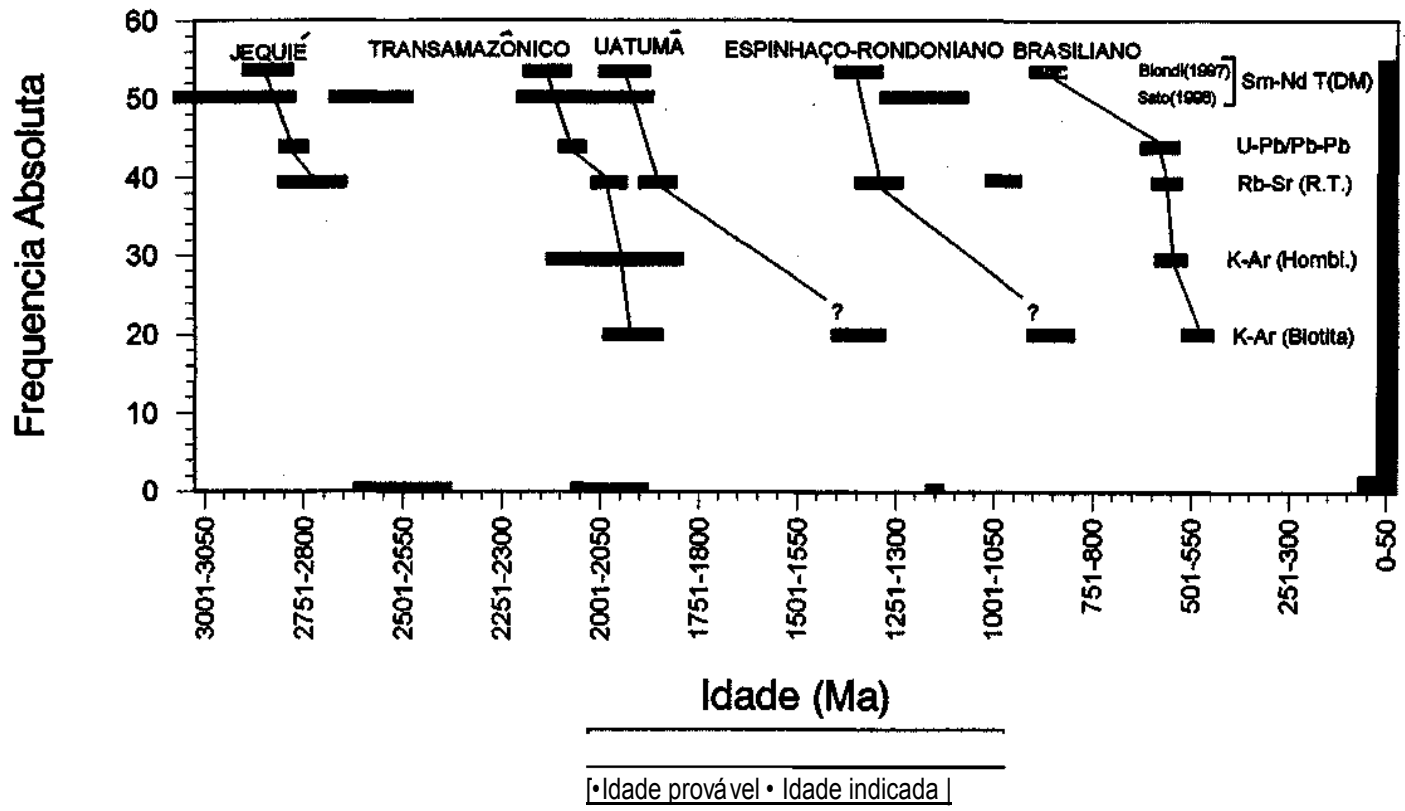

Figura 2 - Idades dos principais depósitos brasileiros originados por enriquecimento supergênico elou residual. Esses depósitos correspondem a 30\% dos 194 depósitos selecionados (Tabela de Biondi, nesse volume). 
depósitos sedimentares químicos dos quais os elementos do minério (Fe, $\mathrm{Au} \mathrm{e} \mathrm{Si)} \mathrm{são,} \mathrm{possivelmente,} \mathrm{de} \mathrm{origem} \mathrm{vulcânica.}$

Os depósitos de Au em BIFs tipo Algoma e em cherts, de Goiás (Crixás), do Pará (Rio Maria) e do Quadrilátero Ferrífero têm idades próximas ou maiores que $2800 \mathrm{Ma}$ (Tabela de Biondi, nesse número) em geral coincidentes mas também um pouco anteriores a acresção de material crustal juvenil relacionada ao Jequié (Fig. 3). O depósito de Morro Velho tem idade questionada por Schrank \& Machado (1996) que, com base em uma idade de 2278 Ma determinada em um zircão detrítico das encaixantes da unidade Lapa Seca, argumentam que a mineralização de Morro Velho seria da época da Formação Sabará. Nesse histograma, foi considerada como idade provável da mineralização desse depósito o intervalo 2772-2780 (Schrank \& Machado 1996, Ladeira 1988). Já os depósitos de metais base têm idades sempre imediatamente posteriores ao final dos eventos de acrescão de material crustal juvenil. Isto acontece (Fig. 3) com o Jequie (depósitos de Pojuca, Salobo, Igarapé Bahia), com o Uatumã (pequenos depósitos SEDEX do Estado do Paraná) e com o Brasiliano (depósitos relacionados ao arco magmático de Goiás). Cada um desses grupos de depósitos será discutido a seguir.

Depósitos vulcanogênicos proximais, tipo VHMS Dentre os 194 depósitos que integram a Tabela de Biondi (nesse número), somente quatro foram reconhecidos como sendo, possivelmente, vulcanogênicos próximos (fig. 4). Os depósitos de $\mathrm{Cu}(\mathrm{Au})$ de Chapada (GO) e de Bom Jardim (GO) e o depósito de $\mathrm{Au}(\mathrm{Ag}, \mathrm{Ba}$ ) de Zacarias (TO) (Tabela de Biondi, nesse número) têm todos idades entre 800 e 900 Ma. Há dúvidas sobre a origem vulcanogênica proximal do depósito de Zacarias (Arantes et al. 1991, Palermo 1996) e, em Chapada, foi interpretada a existência de uma primeira fase de mineralização que seria vulcanogênica, modificada posteriormente por hidrotermalismo associado a intrusões graníticas (Kuyumijian 1998). Todos esses depósitos relacionam-se ao arco magmático de Goiás (Pimentel \& Fuck 1992). Igarapé Bahia, em Carajás, é o único depósito Arqueano (Fig. 4, tabela de Biondi, nesse número) desse grupo. Reconhecido inicialmente como vulcanogênico proximal (VHMS), esse modelo passou a ser questionado recentemente (Tallarico et al. 1998a, Tallarico et al. 1998b, Oliveira et al. 1998, Tavaza et al. 1998) sendo proposta uma génese segundo o modelo Olimpic Dam.

Comparadas com as idades de depósitos VHMS de outros países (Goodfellow et al. 1993, Barley 1992, Kerrich 1992), nota-se que Igarapé Bahia enquadra-se no grupo com maior frequência, entre 2550 e $2750 \mathrm{Ma}$ (Fig. 4), correlacionado, no Brasil, à época de cristalização/resfriamento de rochas do Jequié. Os outros depósitos brasileiros, situados entre 800 e $900 \mathrm{Ma}$, têm idades que não coincidem com as de depósitos de outros países, embora bem situadas em relação a acresção de material crustal juvenil brasiliana. Esta correlação entre depósitos SEDEX e VHMS, e os períodos de maior atividade de segregação mantélica dos eventos termo-tectônicos tem a ver com o ambiente no qual esses depósitos são gerados. São depósitos subma- rinos formados junto a arcos de ilhas, a dorsais medio-oceânicas ou em ambientes sob início de oceanização (Goodfellow et al. 1993, Franklin 1993). Em todos esses casos, as manifestacões vulcânicas geneticamente relacionadas a esses depósitos são imediatamente subsequentes aos eventos de segregação mantélica que iniciam os eventos termo-tectônicos. E isto que se observa nas figuras 3,4 e 5.

Depósitos vulcanogênicos distantes, tipo SEDEX A figura 5 mostra a distribuição das idades dos depósitos brasileiros de $\mathrm{Pb}, \mathrm{Zn}$, $\mathrm{Cu}$ considerados do tipo SEDEX, dos depósitos brasileiros estratiformes e não estratiformes de Au (Kerswill 1993) relacionados a BIF's e a cherts e de depósitos SEDEX de outros países (Goodfellow et al. 1993, Barley 1992, Kerrich 1992).

Pojuca e Salobo, situados na Serra dos Carajás, são depósitos do Arqueano considerados do tipo SEDEX (tabela de Biondi, nesse número). A figura 5 mostra que não são conhecidos outros depósitos SEDEX dessa época, típica de depósitos VMS (Fig. 4). Salobo e Pojuca têm géneses complexas e suas características originais foram modificadas por hidrotermalismo relacionado a granitos, por metamorfismo e por deformacão, o que dificulta, e faz com que não haja consenso, sobre seus modelos genéticos. E possível que esses depósitos sejam do tipo VHMS e constituam, talvez junto ao Igarapé Bahia (Fig. 4), um grupo de depósitos vulcanogênicos relacionado geneticamente à acresção do Ciclo Jequié.

Após o período de maior atividade de acrescão da época Uatumã (Biondi 1977 b, c, d), no intervalo entre 1500 e 1850 Ma formaram-se os depósitos de $\mathrm{Pb}, \mathrm{Zn}, \mathrm{Ag}$ da região do Vale do Ribeira, no Paraná e São Paulo (Tabela de Biondi, nesse número). São depósitos estratiformes, com reservas pequenas, encaixados em rochas carbonatadas do Grupo Setuva. Galena desses depósitos foram datadas pelo método $\mathrm{Pb}-\mathrm{Pb}$ (Daitx 1996, Tabela de Biondi, nesse número).

Comparado aos outros países (Fig. 5), concomitante aos depósitos paranaenses formou-se a maior parte dos depósitos SEDEX da índia e da Austrália (Goodfellow et al. 1993). Esse período, junto a outro entre 300 e 600 Ma (Fig. 5), caracteriza as épocas de maior frequência mundial de ocorrência de depósitos SEDEX. Não foram identificados no Brasil depósitos SEDEX ou VMS com idades típicas desse segundo intervalo. As bacias "molássicas" tipo Castro e Guaratubinha (Paraná) Campo Alegre e Itajaí (Santa Catarina), e Camaquã (Rio Grande do Sul), são unidades vulcanogênicas dessa época que podem ser alvos para esses tipos de depósitos.

Os depósitos de $\mathrm{Au}$ geneticamente relacionados a formações ferríferas bandadas tipo Algoma e a cherts são depósitos sedimentares químicos submarinos formados em ambientes vulcânicos a partir da precipitação de fluidos de origem vulcânica. Por se relacionarem espacial e geneticamente aos depósitos vulcanogênicos, as idades dos depósitos de $\mathrm{Au}$ desse tipo foram incluídas na figura 5. Depósitos Arqueanos desse tipo (Tabela de Biondi, nesse número) existem em Crixás (Mina III, Meia Pataca), na Serra das Andorinhas (Babaçu, Lagoa Seca e Mamão) e no Quadrilátero Ferrífero (Morro Velho,

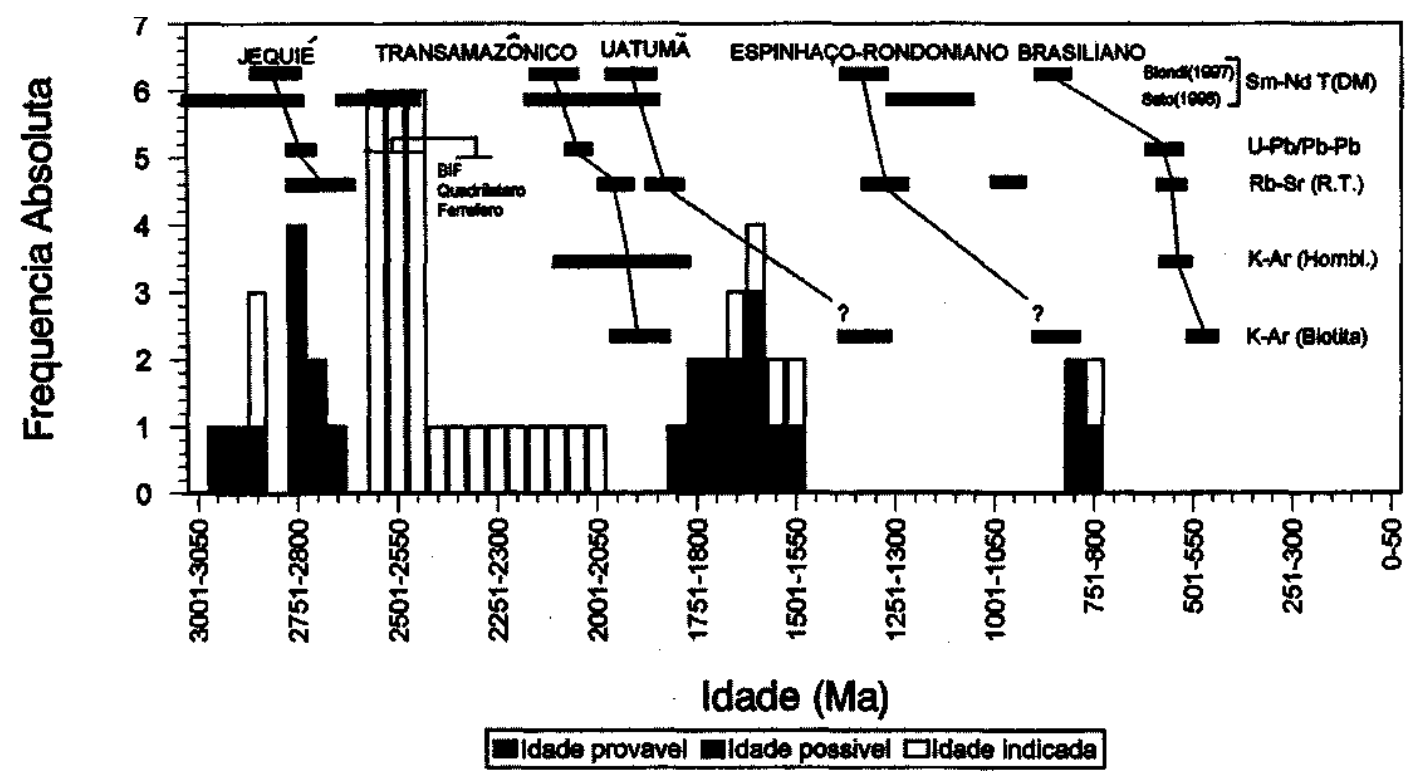

Figura 3 - Idades dos principais depósitos vulcanogênicos proximais e distais brasileiros comparadas aos principais eventos termo-tectônicos que afetaram a plataforma brasileira. 
Raposos, Cuiabá, São Bento). No Quadrilátero Ferrífero o depósito de Morro Velho tem idade discutida, conforme mencionado anteriormente, sendo sugerida uma idade de cerca de 2278 Ma para esse depósito (Tabela, fíg. 5). As idades desse grupo de depósitos, situadas entre 2750 e $3000 \mathrm{Ma}$, coincidem com a época de maior atividade de acresção de material crustal juvenil do evento termo-tectônico Jequié e antecedem a possível época de génese de Salobo, Pojuca e Igarapé Bahia. O depósito de São Francisco, no Rio Grande do Norte, é o único depósito reconhecido como sendo desse tipo com idade indicada entre 1500 e $1700 \mathrm{Ma}$, posterior ao Arqueano.

Palmeirópolis, em Goiás, é o único depósito vulcanogênico brasileiro para o qual foi proposto o modelo Besshi (Tabela de Biondi, nesse número). A idade desse depósito é mal definida, havendo apenas uma indicação de 2000-2500 Ma. Chapada (Goiás), Salobo, Pojuca e Igarapé Bahia (Pará), são depósitos que, pelas características das suas rochas encaixantes, composição do minério e processo genético reconhecido, poderiam eventualmente ser do tipo Besshi.

DEPÓSITOS TIPO MISSISSIPI VALLEY (MVT) Morro Agudo, o maior depósito brasileiro de $\mathrm{Zn}$ e $\mathrm{Pb}$ em tonelagem de minério, tem génese controversa, sendo considerado diagenético por alguns (vide Dardenne \& Freitas-Silva 1998) e tipo Mississipi Valley, subtipo irlandês (Irish Type), por outros (Oliveira 1998, Misi et al. 1998). A provável idade de formacão do minério de Morro Agudo é $1200 \mathrm{Ma}$ considerada época de sedimentação. Posteriormente teria ocorrido um enriquecimento hidrotermal, há $810 \mathrm{Ma}$ (Tabela de Biondi, nesse número).

Os depósitos de $\mathrm{Pb}$ e Ag do Vale do Ribeira, no Paraná, também têm idades próximas de 1200 Ma. São depósitos filonianos, com recursos pequenos (menores que 500.000 ton de minério), encaixados em rochas carbonatadas do Grupo Açungui. Galena desses depósitos foi datada pelo método $\mathrm{Pb}-\mathrm{Pb}$ e os resultados indicaram que o chumbo seria remobilizado das rochas metas sedimentares encaixantes (Daitx 1996). Também nesse caso não há consenso entre os autores, mas esses depósitos poderiam ser do tipo Mississippi Valley (Tabela de Biondi, nesse número)

Morro Agudo e os depósitos filonianos do Vale do Ribeira têm idades entre 1000 e $1300 \mathrm{Ma}$, pouco comuns entre os depósitos Mississipi Valley de outros países (Fig. 6). Na síntese feita por Leach \& Sangster (1993) sobre os depósitos tipo Mississippi Valley de todo o mundo, foram reconhecidos somente 3 depósitos do Neoproterozóico, 2 do Mesoproterozóico e 1 do Paleoproterozóico (Fig. 6). Os depósitos americanos, canadenses e australianos, que integram as maiores províncias conhecidas de depósitos desse tipo, têm idades entre 100 e $600 \mathrm{Ma}$ (Fig. 6), bem posteriores aos depósitos brasileiros.

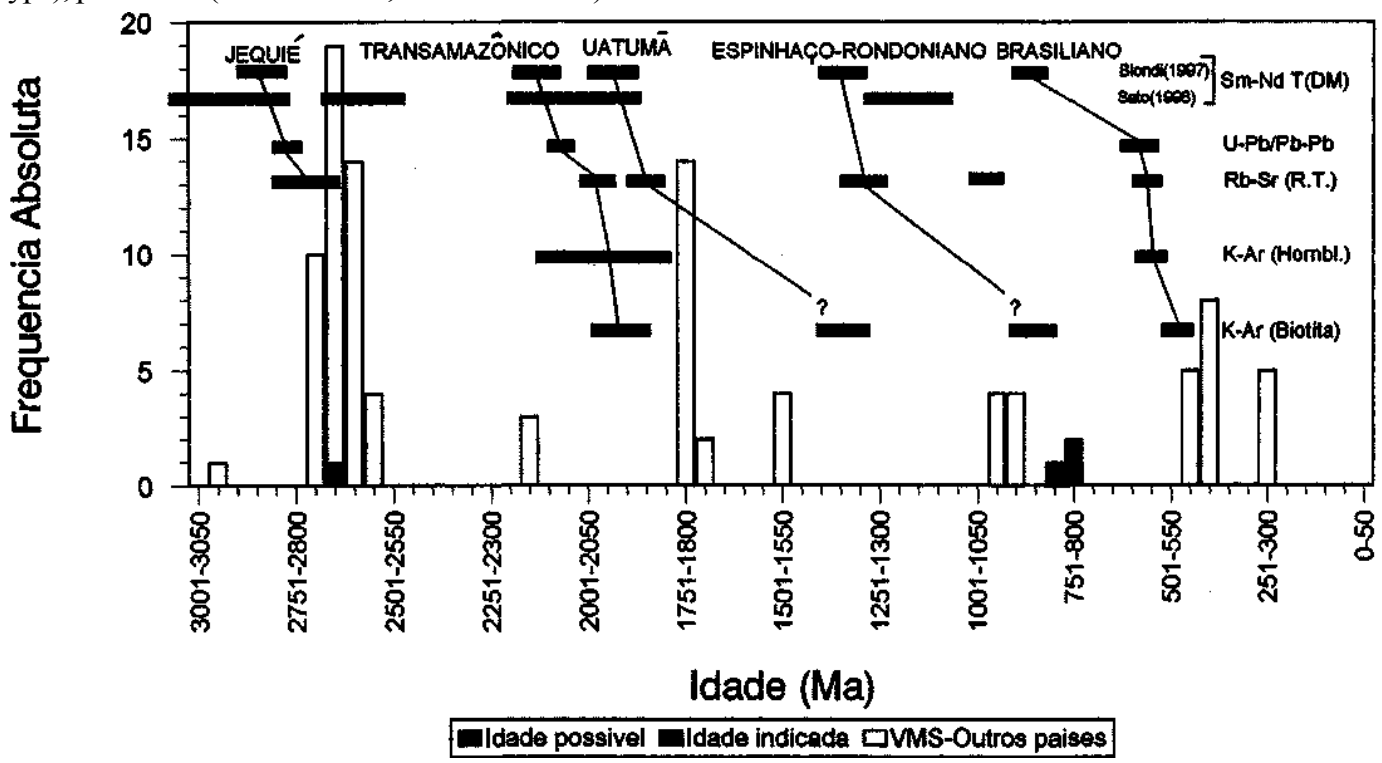

Figura 4 - Idades dos principais depósitos vulcanogênicos próximos (VHMS) brasileiros, tipoAbitibi, comparadas às idades de depósitos VHMS de outros países e aos principais eventos termo-tectônicos brasileiros.

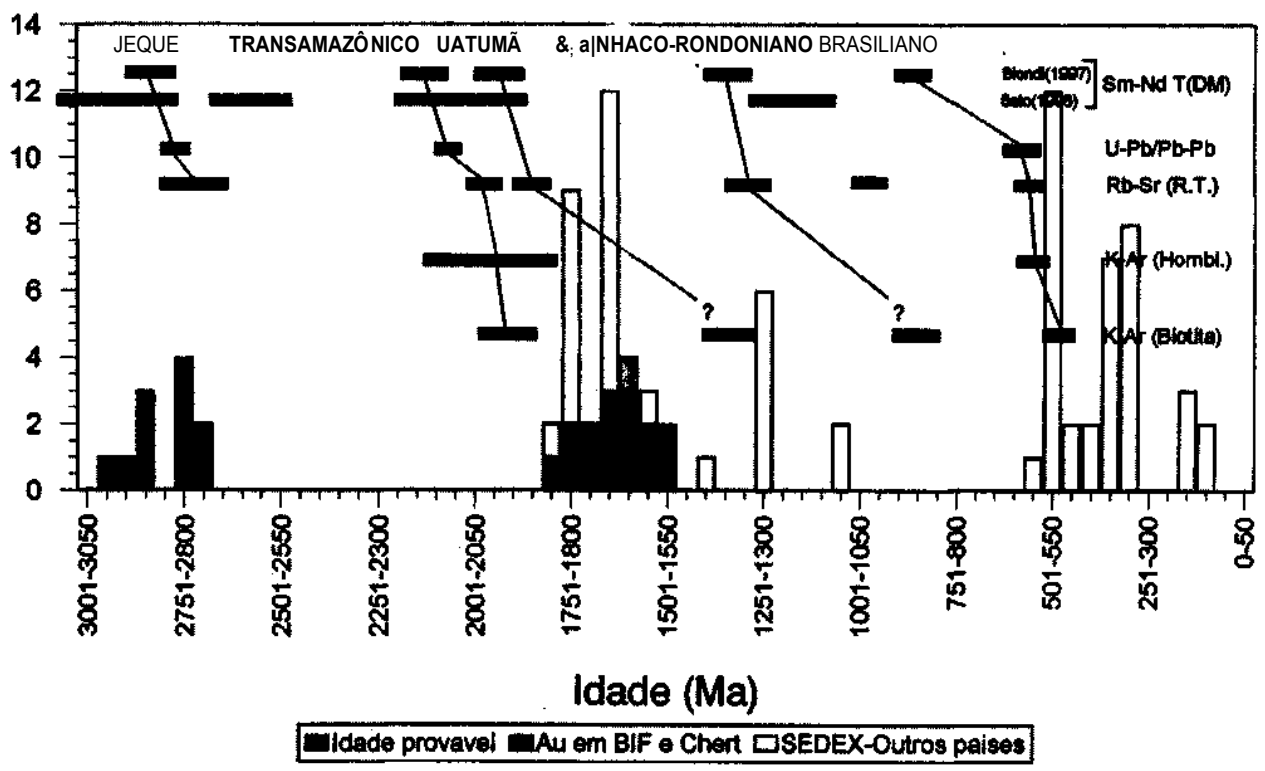

Figura 5 - Idades dos principais depósitos brasileiros tipo SEDEX e tipo Au em BIF's e cherts, comparadas às idades de depósitos SEDEX de outros países e aos principais eventos termo-tectônicos ocorridos no Brasil. 
Misi et al (1998) incluem os depósitos de $\mathrm{Pb}, \mathrm{Zn}, \mathrm{Ag}$ de Nova Redenção e da Serra do Ramalho, na Bahia, entre depósitos do tipo Mississippi Valley. Poderia pertencer a mesma categoria o depósito da Fazenda Rufino, em Irecê, Bahia (Misi et al. 1998, Misi \& Glória da Silva 1996). Esses autores consideram que esses três depósitos formaram-se no período entre 600 e $650 \mathrm{Ma}$, muito próximo do período de maior frequência mundial de ocorrência desses depósitos.

Depósitos tipo Mississippi Valley formam-se nas épocas de soerguimento dos cinturões orogênicos distantes que margeiam as bacias de sedimentação com plataformas carbonatadas, plataformas, estas, onde situam-se os depósitos. Em alguns casos extremos, a mineralização formou-se até 200 milhões de anos após a sedimentação das encaixantes (Leach \& Sangster 1993). Comparadas às idades dos eventos termo-tectônicos brasileiros (Fig. 6, Biondi 1997 a, b, c), os depósitos brasileiros mencionados, com possibilidades de serem do tipo Mississippi Valley, situam-se em épocas apropriadas, logo após as intrusões graníticas dos eventos Espinhaço-Rondoniano e Brasiliano, identificados pelas datações U-Pb, $\mathrm{Pb}-\mathrm{Pb}$ (cristalização) e $\mathrm{Rb}-\mathrm{Sr}$ em rocha total (início do resfriamento).

DEPÓSITOS DE OURO EM ZONAS DE CISALHAMENTO Os melhores exemplos de depósitos brasileiros de Au em zonas de cisaIhamento são Fazenda Brasileiro e Maria Preta, no greenstone belt do Itapicuru, na Bahia, com idades entre 2031 e 2083 Ma (tabela 1, fig. 7). Cabaçal I (MT), com 1750-1900 Ma, Salamangone-Mutum (AP), com idades indicadas entre 2600 e 2900 Ma, e Serra Pelada (PA), com idade entre 1830 e 1859 Ma são também considerados depósitos geneticamente relacionados a zonas de cisalhamento.

Os depósitos de ouro do Quadrilátero Ferrífero, nas suas condições atuais são considerados, em parte, remobilizações para zonas de cisalhamento de concentrações primárias sedimentares químicas de derivação vulcânica. Morro Velho e, .provavelmente, Raposos e Farias, foram recristalizados e ao menos parte do ouro desse depósitos foi reconcentrado em zonas de cisalhamento há 1843 Ma e $462 \mathrm{Ma}$ (Schrank \& Machado 1996a). Em Cuiabá e Carrapato esses mesmos autores detectaram evidências de recristalização e remobilização há 1808 e 590 Ma (Schrank \& Machado 1996b). Os filões mineralizados da Mina de Passagem de Mariana cristalizaram-se entre 2067 e 2093 Ma (Schrank \& Machado 1996a). Essas datações caracterizam épocas de recristalização e remobilização em zonas de cisalhamento que coincidem com os períodos de cristalização/resfriamento dos eventos Transamazônico, Uatumã e Brasiliano (Fig. 7).

Comparadas às idades dos depósitos mesotermais de ouro (Kerswill 1993) de outros países (Barley 1992, Kerrich 1992), os depósitos brasileiros estão dissociados das principais épocas nas quais esse depósitos formaram-se (Fig. 7). Apenas Serra Pelada (PA), com idade indicada entre 2708 e 2778 Ma, e Salamangone/Mutum (AP), com idades indicadas entre 2600 e $2900 \mathrm{Ma}$ (Tabela de Biondi, nesse número), situam-se no período 2600-3000 Ma, de maior incidência mundial de depósitos mesotermais de ouro. Além desse período, em outros países os intervalos 2200-2300 e 150-400 Ma são portadores de quantidades significativas de depósitos de Au em zonas de cisalhamento. No Brasil não foi relatada a existência de depósitos desse tipo nesses períodos.

DEPÓSITOS DE FERRO E MANGANÊS Os maiores depósitos brasileiros de ferro situam-se no Quadrilátero Ferrífero e na Serra dos Carajás. Em ambas as regiões são lavrados minérios formados por enriquecimento residual e supergênico sobre formações ferríferas bandadas gigantes do tipo Superior. O minério primário é constituído por sedimentos químicos depositados entre 2420 e 2600 Ma (Tabela de Biondi, nesse número) no Quadrilátero Ferrífero e entre 2750-2800 Ma em Carajás (Fig. 8). Na Serra dos Carajás as formações ferríferas ( $\approx 2757 \mathrm{Ma}$ ) antecedem os depósitos vulcanogênicos do Igarapé Bahia ( $2700 \mathrm{Ma}$ ), Salobo e Pojuca (2732-2742 Ma), relacionados a formações ferríferas tipo Algoma, de pequeno porte, e com minérios muito ricos em ferro. No Pará e em Minas Gerais as formações ferríferas do tipo Superior depositaram-se em épocas de acresção crustal juvenil (Fig. 8).

$\mathrm{O}$ minério de manganês lavrado no Brasil, a exemplo do ferro, também é consequência do enriquecimento residual e/ou supergênico de minérios primários antigos, do Paleoproterozóico e Arqueano. Os depósitos da Serra do Buritirama e do Azul (Carajás), da Serra do Navio (Amapá), e da Pedra Preta e Barnabé (Bahia), foram formados por enriquecimento residual e/ou supergênico sobre protominério com rodocrosita. Os protominérios de Carajás são Arqueanos, os da Serra do Navio do Paleoproterozóico e os da Bahia, embora não tenham sido datados, devem, também, ser do Paleoproterozóico (Fig. 8 e Tabela de Biondi, nesse número). Em Ventador, Tauá e Lagoa D'Anta, na Bahia, os protominérios são gonditos do Paleoproterozóico, e Miguel Congo e Lafaiete, em Minas Gerais, são derivados de formações ferríferas Arqueanas.

A exceção seria o depósito do Urucum, no Mato Grosso. Considerado de origem sedimentar flúvio-lacustriana a marinha rasa, a época de sedimentação desse depósito é estimada entre 850 e $950 \mathrm{Ma}$ (Tabela de Biondi, nesse número). Este período não coincide com nenhum outro que tenha originado depósitos de Mn ou de Fe no Brasil.

DEPÓSITOS DE ESTANHO Todos os depósitos de estanho de Rondônia e do Amazonas são aluviões derivados do desmantelamento de pegmatitos, greisens e filões de greisen. Em alguns pouco casos, como Potosi (RO), Pedra Branca e Riacho dos Cavalos (GO) e Pitinga (AM), foram ou estão sendo lavrados também os depósitos primários. Datações recentes feitas na Província Estanífera Rondoniana permitiram reunir os granitos estaníferos em quatro grupos, a saber, Serra da Providência (1554-1606 Ma), Santo António (1387-1406 Ma), São Lourenço-Caripunas (1314-1309 Ma) e Potosi-Oriente Novo-Pedra Branca (998-1081 Ma). Os depósitos de São Francisco, no Mato

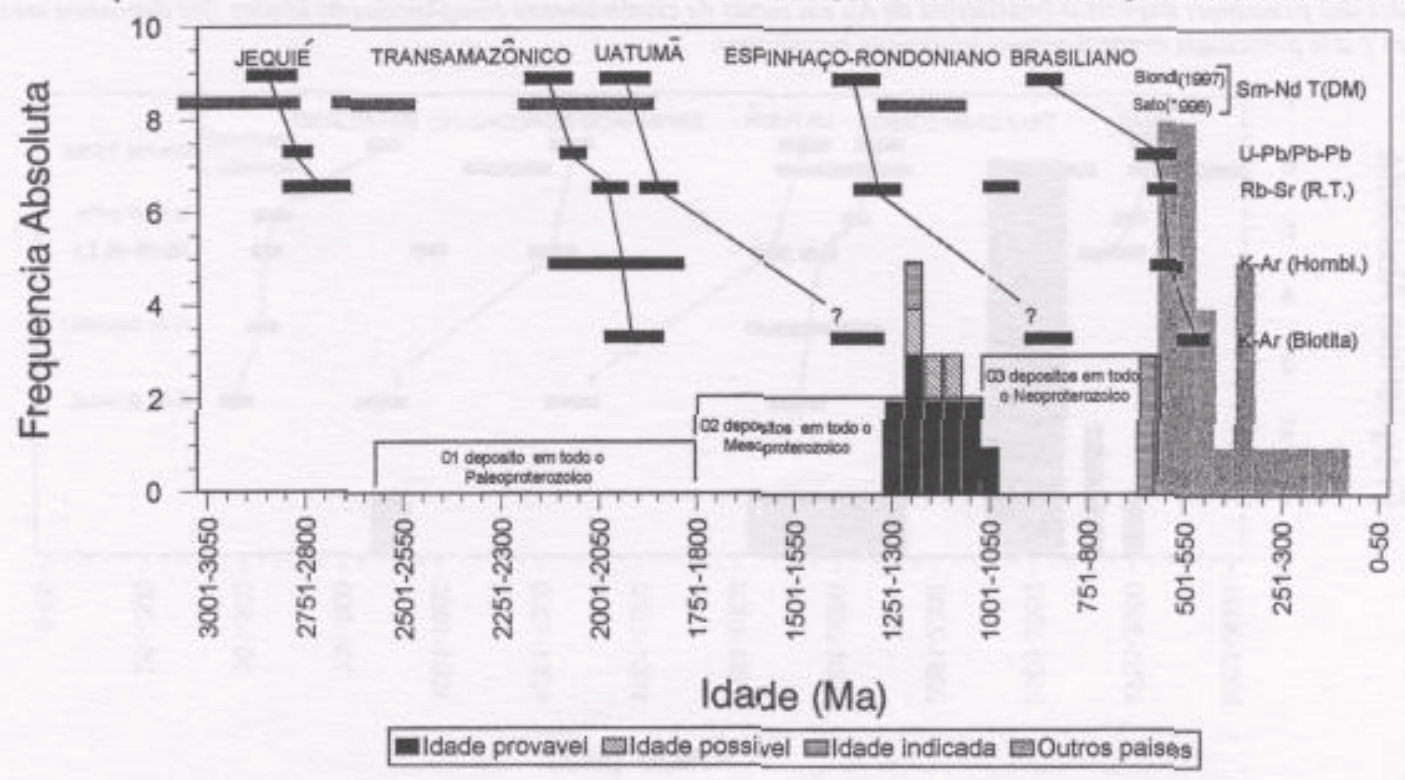

Figura 6 - Idades dos principais depósitos brasileiros que podem ser do tipo Mississippi Valley (MVT) comparadas às idades de depósitos do mesmo tipo de outros países. Em outros países a maior parte dos depósitos desse tipo formaram-se entre 100 e 600 Ma, tendo sido reconhecidos somente 3 depósitos com idades Neoproterozóicas, 2 do Mesoproterozóico e l do Paleoproterozóico. 
Grosso (998-1606 Ma), e do Igarapé Preto, no Amazonas (1309-1314 $\mathrm{Ma}$ ), constituiriam um quinto e um sexto grupos, dessa mesma época. Esses granitos precedem, são contemporâneos e antecedem o evento Rondoniano, do Mesoproterozóico do norte do país (Fig. 9), cujo máximo de atividade termotectônica ocorreu entre 1450 e 1250 Ma. Pitinga (Amazonas), com 1689 Ma, e Surucucus (Roraima), com idade indicada de 1500-1800 Ma seriam predecessores desse evento de mineralização, com idades melhor correlacionáveis à época Uatumã. Granitos da província do Paranã (Goiás), foram datados recentemente (Tabela de Biondi, nesse número) em 2023-2277 Ma, caracterizando um evento transamazônico de mineralização em estanho, até então desconhecido (Fig. 9).

DEPÓSITOS DE URANNIO E FOSFATO Todo o fosfato produzido no Brasil provém da lavra de carbonatitos ou da concentração residual de apatita em carbonatitos. Os carbonatitos fazem parte de complexos alcalinos Mesozóicos, a exemplo de Anitápolis, Gatalão e Jacupiranga, entre outros. Angico dos Dias, situado no noroeste da Bahia, foi datado em 2011 Ma e é o único exemplar brasileiro mineralizado de idade proterozóica. Patos de Minas (MG) e Itataia (CE) têm sido interpretados como fosforitos marinhos. Suas idades estão mal definidas, acreditando-se que Patos de Minas seja do Brasiliano e que Itataia do Paleoproterozóico (Fig. 10, Tabela de Biondi, nesse número).

Lagoa Real e Itataia, os maiores depósitos brasileiros de urânio, e Espinharas, são interpretados como sendo do tipo "urânio em episienitos" (Tabela de Biondi, nesse número). Apesar de pertencerem a mesma categoria, teriam idades muito diferentes, Itataia sendo considerado do Paleoproterozóico enquanto Lagoa Real foi datado em 820 Ma e Espinharas em 395-450 Ma (Fig. 10, Tabela de Biondi, nesse número).

Todos os demais depósitos são de modelos diferentes. Figueira, no Paraná (225-250 Ma) é sedimentar pós-diagenético, Campos Belos e Rio Preto, em Goiás (2000 Ma), relacionam-se geneticamente a zonas de cisalhamento, Amorinópolis, também em Goiás (390 Ma), é do tipo "rolo", Moeda, no Quadrilátero Ferrífero (2420-2606 Ma), é um paleo-aluvião tipo Witwatersrand e Usamu Utsumi (Cercado), em Minas Gerais (60-87 Ma), é um depósito gerado por hidrotermalismo associado ao Complexo Alcalino de Pocos de Caldas. Esta multiplicidade de tipos de depósitos e de épocas de mineralização é típica do urânio, causada pela sua grande mobilidade em todos os ambientes geológicos.

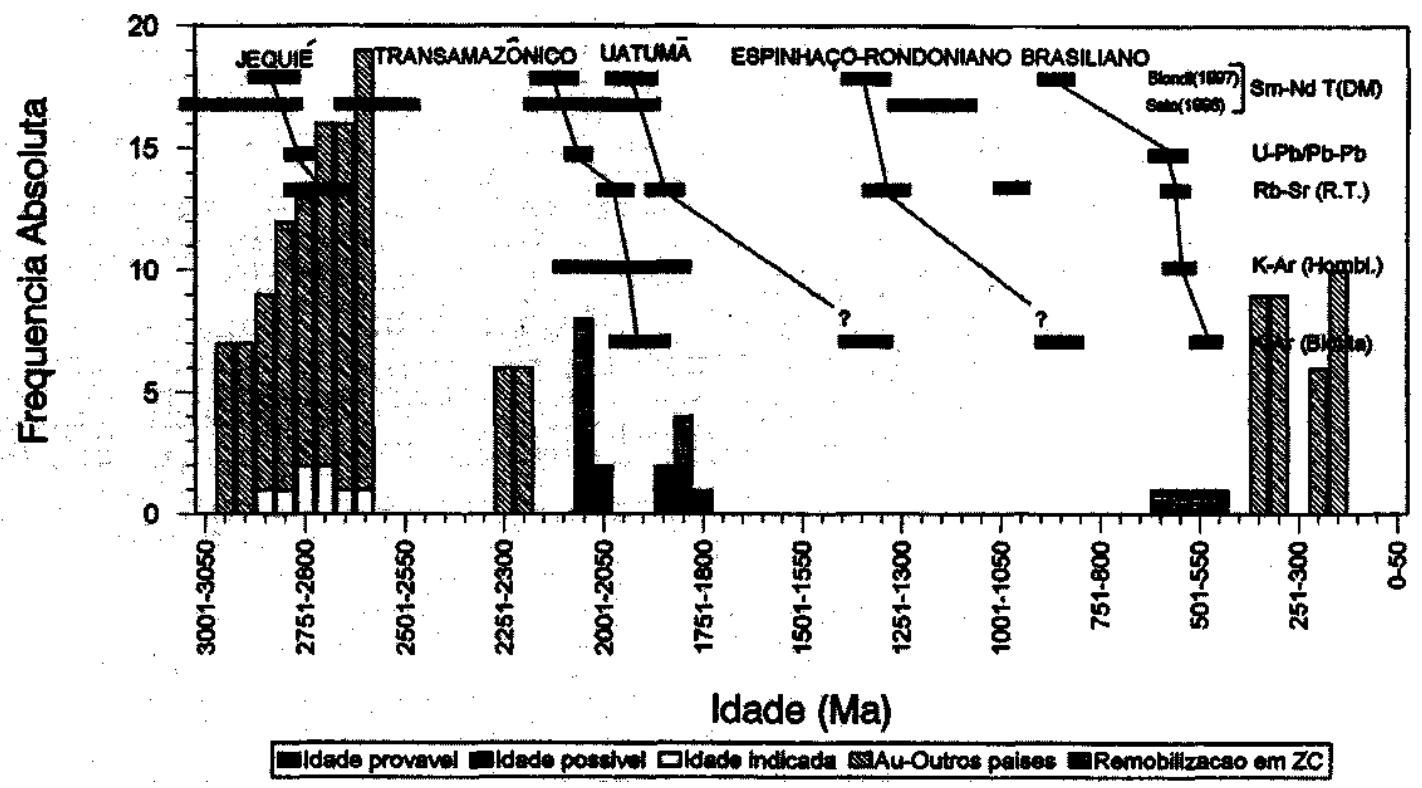

Figura 7 - Idades dos principais depósitos brasileiros de Au em zonas de cisalhamento comparadas às idades dos depósitos mesotermais de Au de outros países e dos principais eventos termo-tectônicos brasileiros.

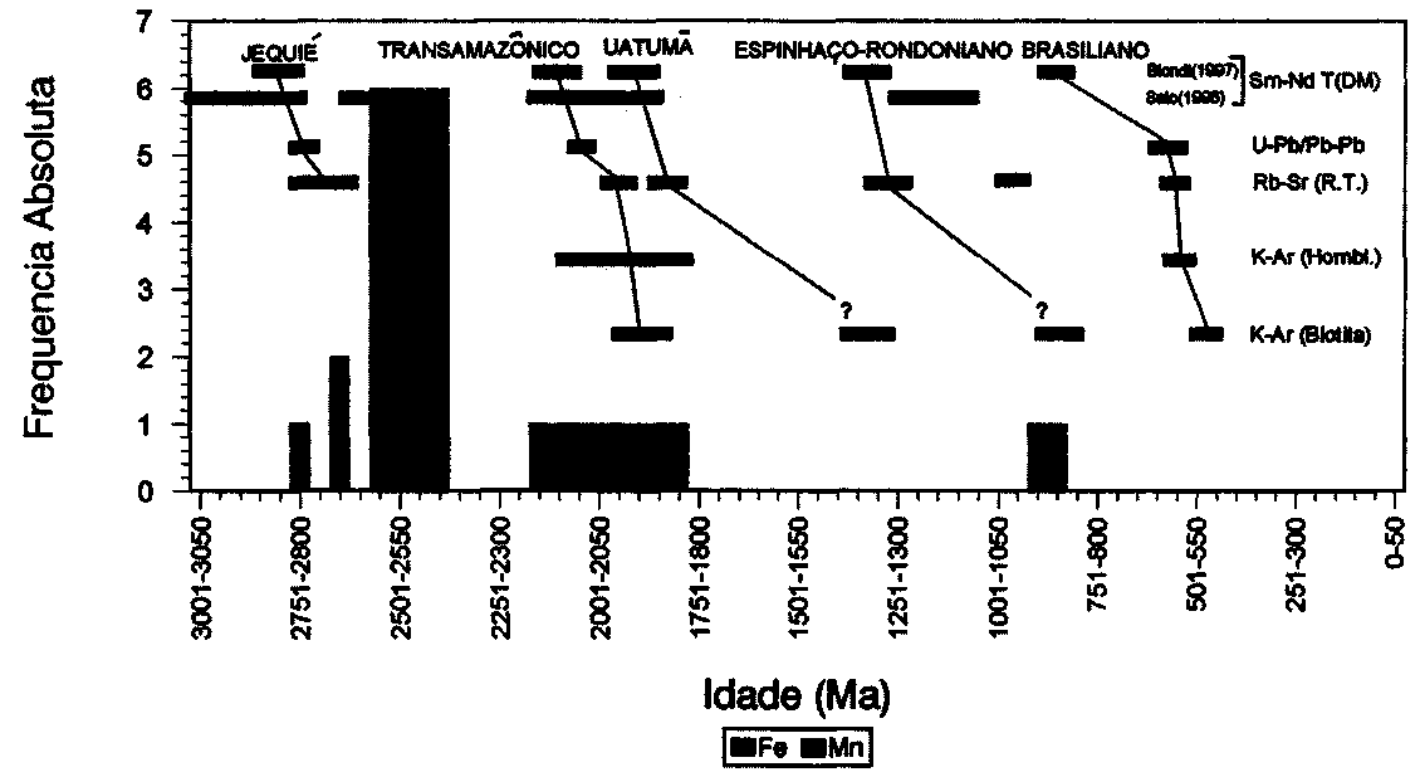

Figura 8 - Idades dos principais depósitos brasileiros de ferro e manganês comparadas as idades dos principais eventos termo-tectomcos brasileiros. 
DEPÓSITOS DE TITÂNIO, NIÓBIO E TERRAS RARAS Exceto Campo Alegre de Lourdes (Bahia), que é um depósito de Ti, V e Fe em anortositos tipo Adirondack com idade estimada entre 2000 e 2200 $\mathrm{Ma}$, os demais depósitos brasileiros de Ti, $\mathrm{Nb}$ e TR são do Mesozóico (Fig. 11, Tabela de Biondi, nesse número) e geneticamente relacionados a complexos alcalinos. Brejo Grande (SE), Mataraca (RNPB) e São João da Barra (RJ) são aluviões marinhos recentes mineralizados a ilmenita, rutilo e zircão.

Barra do Itapirapã (SP-PR) e Mato Preto (PR), ambos com idades entre 60 e $90 \mathrm{Ma}$, são depósitos associados a intrusões alcalino-carbonatíticas particularmente importantes por conterem carbonatos de Terras Raras (série bastnaesita - sinchisita), diferenciando-se de Catalão (GO), Araxá (MG) e do Morro dos Seis Lagos (AM) onde as Terras Raras estão contidas em fosfatos (série monazita -florencita), muito mais difíceis de serem beneficiados. Mato Preto é lavrado para flúor e nenhum desses dois depósitos com bastnaesita-sinchisita é lavrado para TR.

DEPÓSITOS BRASILEJROS DE PEDRAS PRECIOSAS As pedras preciosas brasileiras são lavradas de depósitos de diversos modelos, quais sejam (Fig. 12, Tabela de Biondi, nesse número):

Os pegmatitos brasilianos (450-550 Ma) da Província Pegmatítica do Leste de Minas Gerais e Espirito Santo são os principais depósitos brasileiros de água marinha e turmalina.

O topázio imperial é lavrado em greisens com 998-1080 Ma na região de Massangana (RO) e em filões com idades estimadas entre 550 e 600 Ma em Ouro Preto (MG).

A ametista provêm de geodos em basaltos da Formação Serra Geral (100-110 Ma) no Rio Grande do Sul, de zonas de cisalhamento (2551-2573 Ma) em Alto Bonito (Carajás, PA) e de aluviões e colúvios Recentes de Pau D'Arco, também no Pará.

$\mathrm{O}$ diamante provém sobretudo de aluviões em rios de várias regiões do país (Tabela de Biondi, nesse número). Somente em Paranatinga (MT) e em Coromandel (MG) foram descobertos kimberlitos mineralizados datados em $121 \mathrm{Ma}$ e 53-87 Ma, respectivamente (Tabela de Biondi, nesse número).

Os depósitos de esmeralda de Santa Terezinha e da região de Minaçu (GO) são geneticamente relacionados a zonas de cisalhamento hidrotermalizadas há 450-500 Ma. Itabira (MG), com idade estimada entre 500 e $700 \mathrm{Ma}$, e Carnaíba (BA), com idade de cerca de 1975 Ma (Tabela, figura 12), são depósitos formados em rochas vulcânicas básicas em contato com pegmatitos.

DEPÓSITOS BRASILEIROS DE MINERAIS E MINÉRIOS INDUSTRIAIS Sob a denominação genérica de "minerais e minérios industriais" costuma-se tratar de minerais e minérios geralmente não metálicos utilizados pela indústria na forma bruta ou muito pouco transformada. A variedade é enorme e os principais são os materiais usados na construção civil (areia, pedra britada, calcário, rochas ornamentais, etc.) não tratados nesse trabalho. Nessa categoria também se enquadram (Fig. 13, Tabela de Biondi, nesse número):

Barita/gipsita: os maiores depósitos brasileiros situam-se na Bahia e compreendem o de Camamu, constituído por barita cimentando arenitos datados em 110-120 Ma, e Ibitiara, de onde a barita é extraída de filões considerados Mesoproterozóicos (1000-1100 Ma).

Caulim: há inúmeros depósitos no Brasil. Os maiores são todos flúvio-lacustrinos do Plioceno (Rio Jari, Rio Capim e Morro do Felipe, no Pará, e Tijucas do Sul, no Paraná). Os depósitos de Campo Alegre são geneticamente relacionados a um hidrotermalismo vulcanogênico com 500-570 Ma seguido de hidrólise e supergênese (Biondi \& Furtado 1999, Biondi 1999 no prelo).

Gipsita/Silvita: são minerais típicos de evaporitos. No Brasil os principais evaporitos são do Senoniano (Bacia do Araripe, PI, PE e CE, com 70-90 Ma) e do Aptiano (Maraú, na Bahia, Aveiro, no Pará, Codó, no Maranhão e Taquari-Vassouras, em Sergipe, com 100-110 Ma).

Magnesita: são depósitos gerados pelo metamorfismo de rochas ultrabásicas. Brumado e Sento-Se, na Bahia, e Orós, no Ceará, são os maiores depósitos brasileiros de magnesita. As rochas ultrabásicas relacionadas a esses depósitos são provavelmente Arqueanas e há dúvidas se o metamorfismo responsável pela génese da magnesita seria Transamazônico (cerca de 2000 Ma) ou Brasiliano (cerca de $550 \mathrm{Ma}$ ). Na figura 13 optou-se pela idade Brasiliana para esses depósitos, levando em conta que o metamorfismo dessa época deve ter recristalizado minerais formados em épocas mais antigas.

Talco: é comum o talco associar-se geneticamente à magnesita, formando-se também pelo metamorfismo de rochas ultrabásicas, como em Brumado (BA). Os depósitos de talco do Paraná (Ponta Grossa e Itaiacoca) e de São Paulo (de Ribeirão Branco) foram formados durante o Brasiliano (550-600 Ma) por metamorfismo e hidrotermalismo de dolomitos.

CONCLUSÕES Embora as idades dos depósitos minerais brasileiros distribuam-se por todas as épocas, desde há $3000 \mathrm{Ma}$, podem ser percebidas frequências menores, ou mesmo a ausência de depósitos, em épocas que antecedem o início da acresção de material crustal juvenil e/ou do resfriamento das rochas formadas em cada um dos principais eventos termo-tectônicos brasileiros. Essas épocas correspondem ao final do ciclo anterior, quando praticamente cessaram todas as atividades térmicas e tectônicas não restando fenómenos energéticos capazes de gerar depósitos minerais primários (que não sejam gerados por processos superficiais, químicos ou gravitacionais). Os máximos de atividade de formação de depósitos coincidem ou sucedem imediatamente às épocas principais de cristalização/resfriamento de cada um dos eventos tectônicos maiores representados pelos

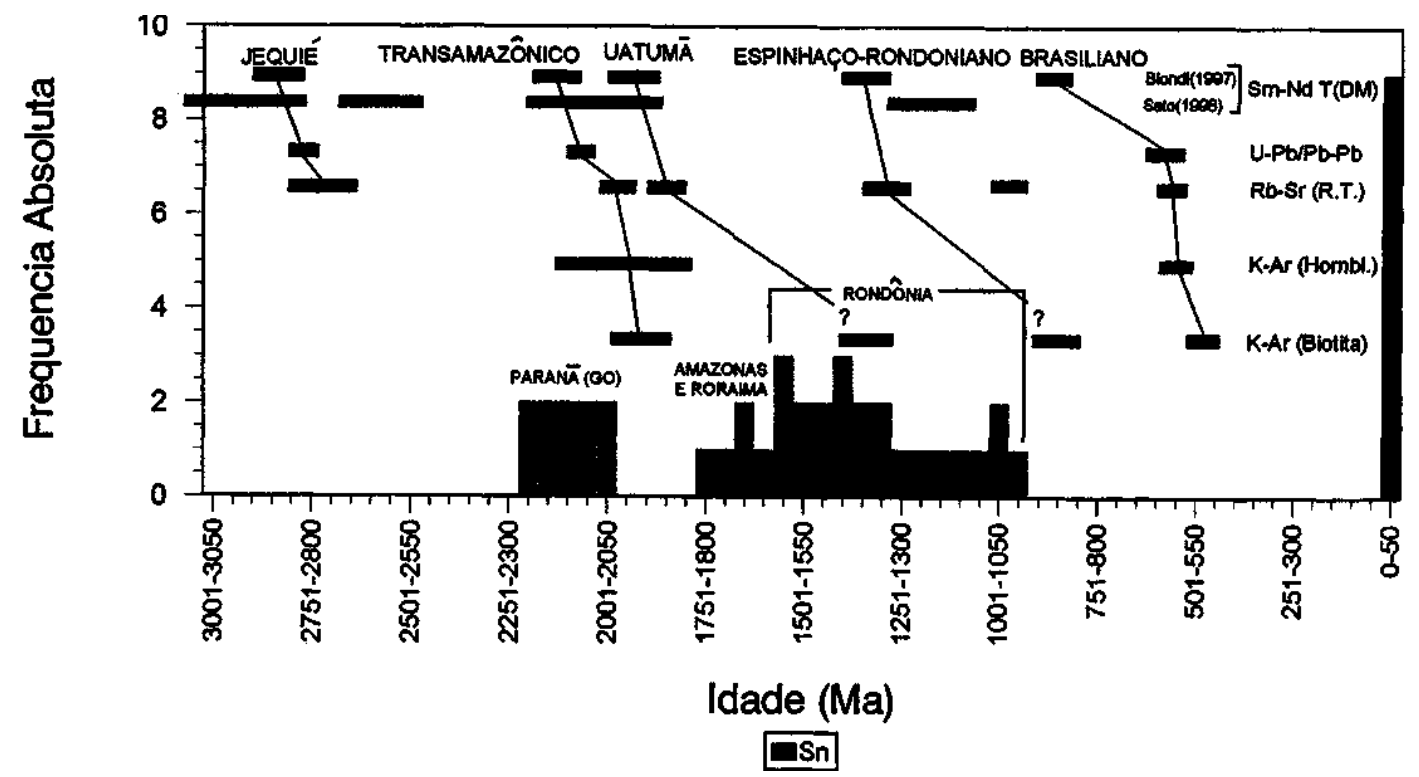

Figura 9 - Idades dos principais depósitos brasileiros de estanho comparadas às idades dos principais eventos termo-tectônicos brasileiros. As trếs principais províncias estaniferas brasileiras (Paraná, em Goiás, a província Amazônica e a província Rondoniana) têm mineralizações primárias geradas em épocas diferentes, mais distribuídas sequencialmente no tempo. 
intervalos 2650-2800 Ma (Jequié), 1950-2150 Ma (Transamazônico), 1000-1250 Ma (após o Espinhaço-Rondoniano) e 450-700 Ma (Brasiliano). Ao contrário dos finais de ciclos, esses períodos correspondem as épocas de maior disponibilidade de energia, térmica e tectônica, na superficie da litosfera, induzindo a formação dos depósitos minerais.

Os depósitos formados por concentrações supergênicas e/ou residuais independem dos eventos termo-tectônicos antigos. Entre os 194 depósitos selecionados, os supergênicos/residuais fazem o maior grupo, constituindo cerca de $30 \%$ do total. Relacionam-se geneticamente sobretudo às superfícies de aplainamento Sul-Americana, Japi e Velhas, todas elas formadas a partir do início do Eoceno, há cerca de 50 Ma. Somado aos pláceres recentes, os depósitos supergênicos/residuais tornam o período de 50-0 Ma a mais importante época metalogenética brasileira.

Comparando as idades dos depósitos vulcanogênicos tipo Abitibi (VMS) brasileiros com as idades de depósitos equivalentes de outros países, nota-se que Igarapé Bahia enquadra-se no grupo com maior frequência, entre 2550 e $2750 \mathrm{Ma}$, correlacionado, no Brasil, à acresção de material crustal juvenil Jequié. Os demais depósitos brasileiros, com idades entre 800 e 900 Ma, não coincidem cronologicamente com depósitos de outros países, embora bem situadas em relação a acresção de material crustal juvenil brasiliana.

Pojuca e Salobo, do Arqueano, situados na Serra dos Carajás, são depósitos considerados do tipo SEDEX. No intervalo entre 1500 e $1850 \mathrm{Ma}$ formaram-se os depósitos de $\mathrm{Pb}, \mathrm{Zn}, \mathrm{Ag}$ da região do Vale do Ribeira, nos Estados do Paraná e São Paulo. Comparado aos outros países, concomitante aos depósitos paranaenses formou-se a maior parte dos depósitos SEDEX da índia e da Austrália. Esse período, junto a um outro entre 300 e $600 \mathrm{Ma}$, caracteriza as épocas de maior frequência mundial de ocorrência de depósitos SEDEX. Não foram identificados no Brasil depósitos SEDEX ou VHMS com idades típicas desse segundo intervalo. Esta correlação entre depósitos vulcanogênicos, SEDEX ou VHMS, e os períodos de maior atividade de segregação mantélica dos eventos termo-tectônicos tem a ver com o ambiente no qual esses depósitos são gerados. São depósitos submarinos formados em arcos de ilhas, dorsais medio-oceânicas ou em ambientes onde esteja ocorrendo início de oceanização. Em todos esses casos, as manifestações vulcânicas geneticamente relacionadas a esses depósi-

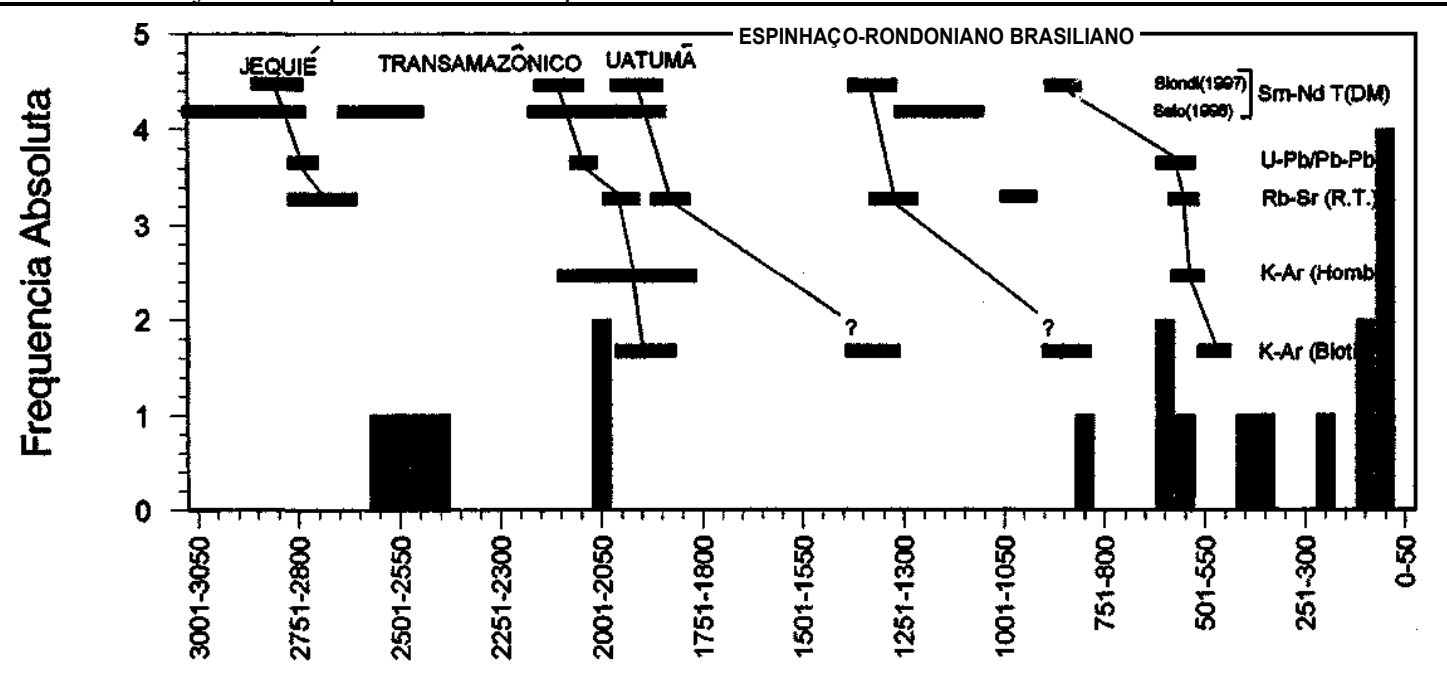

Idade (Ma)

[०u $\mathrm{mpl}$

Figura 10 - Idades dos principais depósitos brasileiros de urânio e fosfato comparadas às idades dos principais eventos termo-tectônicos brasileiros. A grande mobilidade geoquímica do urânio causa a diversidade de tipos de depósitos existentes no Brasil, aparentemente distribuidos sem controle dos eventos termo-tectônicos.

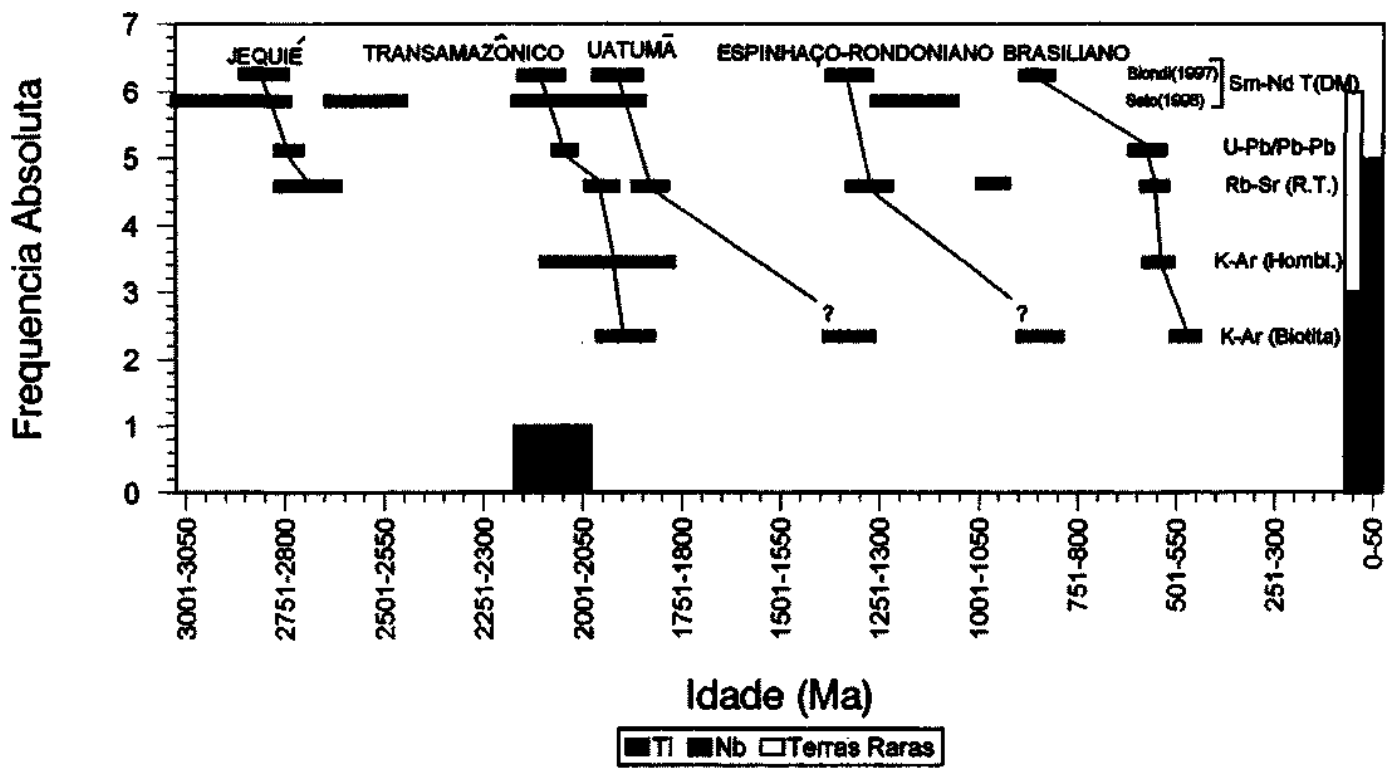

Figura 11 - Idades dos principais depósitos brasileiros de titânio, nióbio e Elementos Terra Raras comparadas às idades dos principais eventos termo-tectônicos brasileiros. Exceto o depósito de Ti de Campo Alegre de Lourdes (BA), todos os outros depósitos relacionam-se geneticamente ao magmatismo alcalino Mesozóico 
tos são imediatamente subsequentes aos eventos de segregação magmática que iniciam os eventos termo-tectônicos.

Os depósitos brasileiros com possibilidades de serem do tipo Mississippi Valley seriam Morro Agudo (MG), os depósitos filonianos do Vale do Ribeira (Paraná), e Nova Redenção, Serra do Ramalho e FazendaRufino (Bahia). Depósitos tipo Mississippi Valley formam-se nas épocas de soerguimento dos cinturões orogênicos distantes que margeiam as bacias de sedimentação com plataformas carbonatadas. Comparadas às idades dos eventos termo-tectônicos brasileiros, os depósitos mencionados situam-se logo após as intrusões graníticas dos eventos Espinhaço-Rondoniano e Brasiliano. Os depósitos americanos, canadenses e australianos, que integram as maiores províncias conhecidas de depósitos desse tipo, têm idades entre 100 e $600 \mathrm{Ma}$, bem posteriores aos depósitos brasileiros.

Comparadas às idades dos depósitos mesotermais de ouro de outros países, os depósitos brasileiros estão dissociados das principais épocas mundiais nas quais esse depósitos se formaram. Apenas Serra Pelada (PA), com idade indicada entre 2708 e $2778 \mathrm{Ma}$, e Salamangone/Mutum (AP), entre 2600 e 2900 Ma, têm idades no período 2600-3000 $\mathrm{Ma}$, de maior incidência mundial de depósitos mesotermais de ouro. No Brasil a maior parte dos depósitos de Au relacionados geneticamente a zonas de cisalhamento, primários ou remobilizados, têm idades coincidentes com as épocas de maior atividade de cristalização/resfriamento do Transamazônico, do Uatumã e do Brasiliano.

O minério primário brasileiro de ferro é constituído por sedimentos químicos depositados entre 2420 e 2600 Ma no Quadrilátero Ferrífero e entre 2750-2800 Ma em Carajás. Os depósitos de manganês da Serra do Buritirama e do Azul, (Carajás), da Serra do Navio, (Amapá), e da Pedra Preta e Barnabé, (Bahia), foram formados a partir de rochas carbonatadas rodocrosíticas. Os minérios primários dos depósitos de Carajás são Arqueanos, os da Serra do Navio são do Paleoproterozóico e os da Bahia, embora não tenham sido datados, devem, também, ser do Paleoproterozóico. Ventador, Tauá e Lagoa D'Anta, na Bahia, têm protominérios gondíticos do Paleoproterozóico, e Miguel Congo e Lafaiete, em Minas Gerais, são derivados de formações ferríferas Arqueanas. A exceção seria o depósito do Urucum, no Mato Grosso. Considerado flúvio-lacustriano a marinho raso, esse depósito tem época de sedimentação estimada entre 850 e 950 Ma. Este período não coincide com nenhum outro período de origem de depósitos de $\mathrm{Mn}$ ou de Fe no Brasil.

Datações recentes na Província Estanífera Rondoniana permitiram agrupar os granitos fornecedores de estanho em quatro grupos denominados Serra da Providência (1554-1606 Ma), Santo Antônio (1387$1406 \mathrm{Ma}$ ), São Lourenço-Caripunas (1314-1309 Ma) e Potosi-Oriente

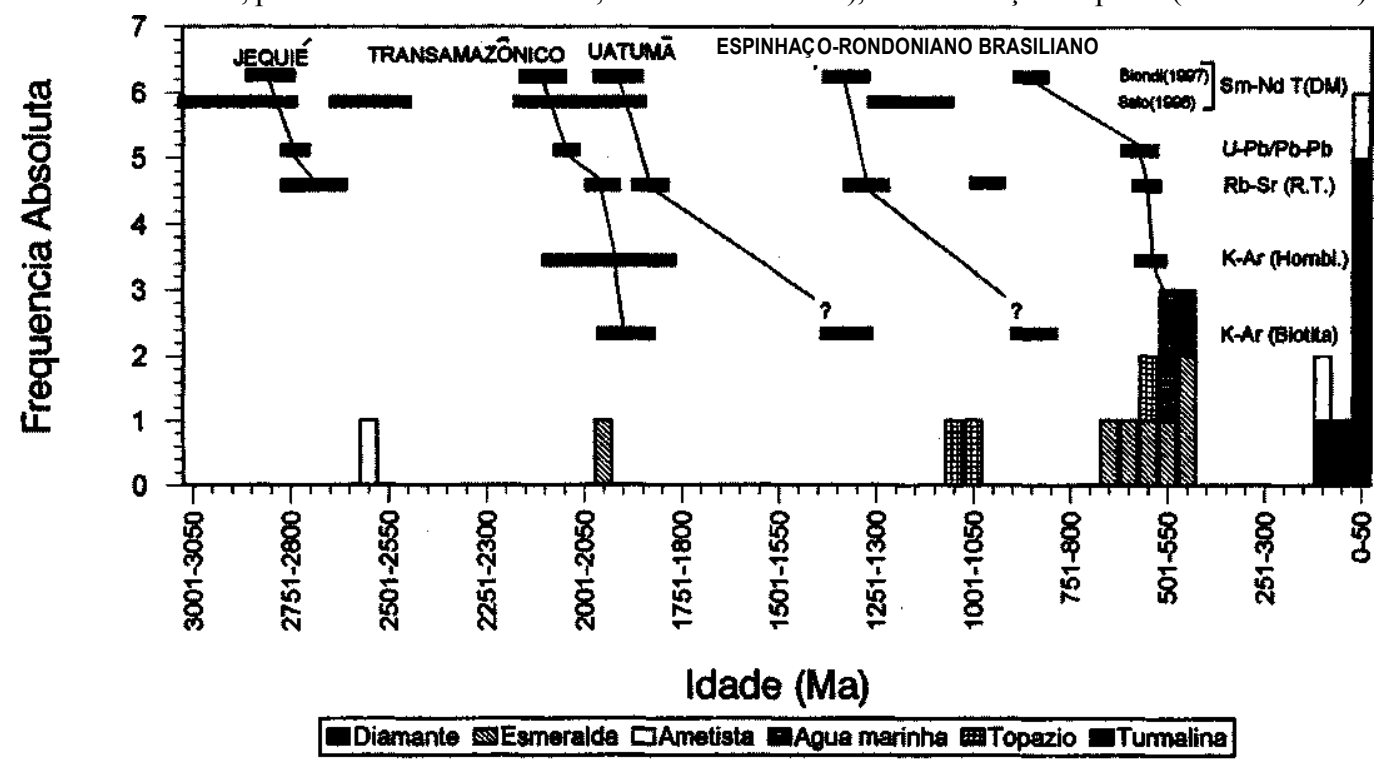

Figura 12 - Idades dos principais depósitos brasileiros de pedras preciosas comparadas às idades dos principais eventos termo-tectônicos brasileiros. O evento Brasiliano foi o principal responsável pela formação de depósitos primários de pedras preciosas no Brasil.

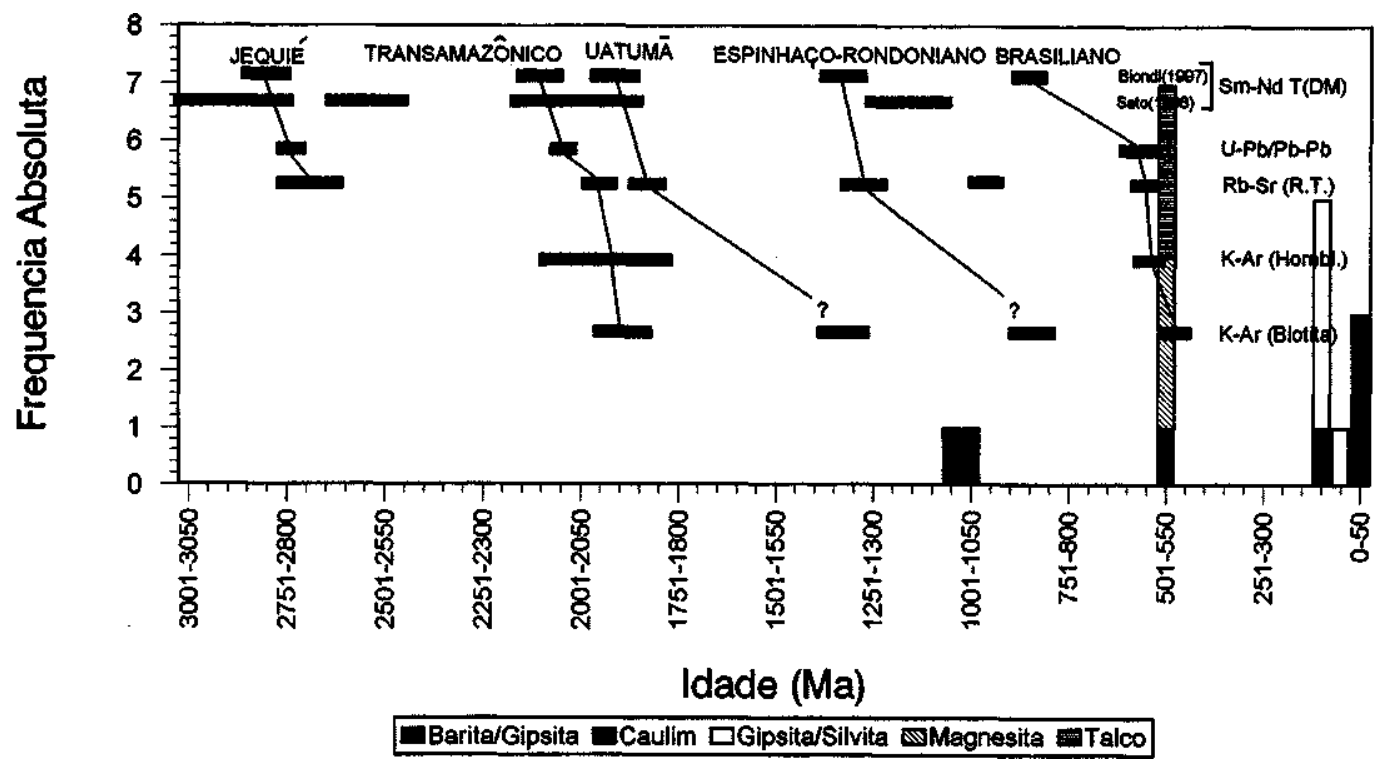

Figura 13 - Idades dos principais depósitos brasileiros de "minerais e minérios industriais" comparadas às idades dos principais eventos termo-tectônicos brasileiros. 
Novo-Pedra Branca (998-1081 Ma). Os depósitos de São Francisco, no Mato Grosso (998-1606 Ma), e do Igarapé Preto, no Amazonas (1309-1314 Ma), fariam um quinto grupo e um sexto grupo, dentro dessa mesma época de mineralização. Esses granitos precedem, são contemporâneos e antecedem o evento Rondoniano (1450-1250 Ma), do Mesoproterozóico do norte do país. Pitinga, no Amazonas, com 1689 Ma, e Surucucus, em Roraima, com idade indicada de 1500-1800 Ma seriam predecessores desse evento de mineralização, com idades melhor correlacionáveis à época Uatumã. Granitos da província estanífera goiana, denominada província do Paranã, foram datados recentemente em 2023-2277 Ma, caracterizando um evento de mineralização em estanho relacionado ao Transamazônico, até então desconhecido.

Lagoa Real, Itataia e Espinharas, são depósitos de urânio interpretados como sendo do tipo "urânio em episienitos". Apesar de serem do mesmo tipo teriam idades muito diferentes, Itataia sendo considerado paleoproterozóico enquanto Lagoa Real foi datado em $820 \mathrm{Ma}$ e Espinharas foi datado em 395-450. Todos os outros depósitos são de modelos diferentes. Figueira, no Paraná (225-250 Ma) é sedimentar pós-diagenético, Campos Belos e Rio Preto, em Goiás (2000 Ma), relacionam-se geneticamente a zonas de cisalhamento, Amorinópolis, também em Goiás (390 Ma), é do tipo "rolo", Moeda, no Quadrilátero Ferrífero (2420-2606 Ma), é um paleo-aluvião tipo Witwatersrand e Usamu Utsumi (Cercado), em Minas Gerais (60-87 Ma), é um depósito

antes D., Osborne G.A., Buck P.S., Porto C.G. 1991. The Mara Rosa volcano-sedimentary sequence and associated gold mineralization. In: E. A. Ladeira (ed.) Brazil Gold' 91. Anais, 221-229.

Barley M.E. \& Groves D.I. 1992. Supercontinent cycle and the distribution of metal deposits through time. Geology, 20:291-294.

Biondi J.C. 1997a. Episodes of igneous and metamorphic granitization in brazilian crust. South Amererican Symposium on Isotope Geology (Campos de Jordão - $B R$ ). Extended Abstracto 1:54-56.

Biondi J.C. 1997b. Principais eventos termo-tectônicos brasileiros descritos com base em idades Sm-NdT(DM), U-Pb, Pb-Pb, Rb-SrE K-Ar: 2. Os eventos termo-tectônicos e seus magmatismos, metamorfismos e gradientes térmicos. Boletim Paranaense de Geociências 45: (no prelo).

Biondi J.C. 1997c. Principais eventos termo-tectônicos brasileiros descritos com base em idades $\mathrm{Sm}-\mathrm{Nd} \mathrm{T}(\mathrm{DM}), \mathrm{U}-\mathrm{Pb}, \mathrm{Pb}-\mathrm{Pb}, \mathrm{Rb}-\mathrm{Sr} \mathrm{E} \mathrm{K}-\mathrm{Ar}$ : 3. Uma síntese sobre granitos e rochas graníticas. Boletim Paranaense de Geociências 45: (no prelo)

BiondiJ.C. 1999. Distribuição no tempo geológico dos principais depósitos minerais brasileiros: 1. Banco de dados. Revista Brasileira de Geociencias, nesse volume.

Brizzi A.S. \& Roberto F.A.C. 1988. Jazida de cobre de Pedra Verde - Viçosa do Ceará, Ceará. In: Schobbenhaus C. \& Coelho C.E.S. (Eds.), 1988. Principais Depósitos Minerais Brasileiros - Metais Básicos Não Ferrosos, Ouro e Alumínio. DNPM, Vol. 3:71-80.

Daitx E. 1996. Origem e evolução dos depósitos sulfetados tipo Perau (Pb-Zn-Ag), com base nas jazidas Canoas e Perau (Vale do Ribeira, PR). UNESP, Tese de Doutorado, $354 \mathrm{p}$.

Dardenne M.A. \& Freitas-Silva F.H. 1998. Modelos genéticos dos depósitos Pb-Zn nos Grupos Bambui e Vazante. In: Depósitos Minerais Brasileiros de Metais-Base, Workshop, Extended Abstracts, 86-93.

Franklin J.M. 1993. Volcanic-associated massive sulphide deposits. In: Kirkham R.V Sinclair W.D., Thorpe R.I., Duke J.M. (eds.) Mineral Deposit Modeling , Special Paper n ${ }^{\circ} 40$, Geol. Assoe. Canada, 315-334.

Goodfellow W.D., Lydon J.W., Turner R.J.W. 1993. Geology and génesis of stratiform sediment-hosted (SEDEX) zinc-lead-silver sulphide deposits. In: Kirkham R.V., Sinclair W.D., Thorpe R.I., Duke J.M. (eds.) Mineral Deposit Modeling , Special Paper n 40 , Geol. Assoe. Canada, 201-251.

Kerrich R. 1992. Secular variation of metal deposits and supercontinent cycles. In: H.L. Barnes (ed.) Geochemistry of Hydrothermal Ore Deposits. Wiley \& Sons, $3^{\circ}$ Ed..

Kerswill J.A. 1993. Models for iron-formation-hosted gold deposits. In: Kirkham R.V. Sinclair W.D., Thorpe R.I., Duke J.M. (eds.) Mineral Deposit Modeling, Special Paper n 40, Geol. Assoe. Canada, 171-199.

Kuyumjian R.M. 1990. As zonas de alteração associadas ao depósito de Cu-Au de Chapada, Goiás, Brasil. . In: SBG, Congresso Brasileiro de Geologia, 36, Natal, Anais, 3:1172-1178.

Ladeira E. A. 1988. Metalogenia dos depósitos de ouro do Quadrilátero Ferrífero, Minas Gerais. In: Schobbenhaus C. \& Coelho C.E.S. (Eds.), 1988. Principais Depósitos Minerais Brasileiros - Metais Básicos Não Ferrosos, Ouro e Alumínio. DNPM, Mol. 3,301-376.

Leach D.L. \& Sangster D.F. 1993. Mississippi Valley-type lead-zinc deposits. In: Kirkham R.V., Sinclair W.D., Thorpe R.I., Duke J.M. (eds.) Mineral Deposit Modeling, Special Paper n 40, Geol. Assoe. Canada, 289-314. gerado por hidrotermalismo associado ao Complexo Alcalino de Poços de Caldas. Esta multiplicidade de tipos de depósitos e de épocas de mineralização é típica do urânio, causada pela sua grande mobilidade em todos os ambientes geológicos.

Com a exceção de Campo Alegre de Lourdes, depósito de Ti, V e $\mathrm{Fe}$ em anortositos tipo Adirondack, situado na Bahia, com idade estimada entre 2000 e $2200 \mathrm{Ma}$, os outros depósitos primários, brasileiros, de Ti, Nb e TR são Mesozóicos e geneticamente relacionados a complexos alcalinos. Dessa mesma época são também os depósitos primários de diamantes em kimberlitos e os depósitos de ametista em basaltos.

O Brasiliano caracteriza-se como a principal época metalogenética brasileira para pedras preciosas lavradas em pegmatitos. Praticamente toda a produção brasileira de água marinha e das diversas variedades de turmalina provém de pegmatitos dessa época, de Minas Gerais, Espirito Santo, Bahia e do nordeste.

É também brasiliano o metamorfismo responsável pela geração da maior parte do talco e da magnesita produzidos no país. Ainda tratando de "minerais industriais", a gipsita, a silvita e a barita provêm de evaporitos com idades variadas entre o Senoniano e o Aptiano.

A dois revisores anónimos da RBG pelas

\section{Agradecimentos}

críticas e sugestões.

\section{eferências}

Misi, A. \& Glória da Silva, M. 1996. Chapada Diamantina Oriental - Bahia: Geologia e Depósitos Minerais. Série Roteiros Geológicos. SGM-Superintendência de Geologia e Recursos Minerais, Governo da Bahia, 194p.

Misi A., lyer S.S., Tassinari C.C.G., Coelho C.E.S., Kyle J.R. 1998. Integrated studies and metallogenic evolution of the proterozoic sediment-hosted Pb-Zn-Ag sulfide deposits of the São Francisco Craton, Brazil. In: Depósitos Minerais Brasileiros de Metais-Base, Workshop, Extended Abstracts, 94-101.

Oliveira C.G., Tazava, E., Tallarico, F., Santos, R.V., Gomes, C. 1998. Génese do depósito de $\mathrm{Au}-\mathrm{Cu}$ (U-ETR) de Igarapé Bahia, Província Mineral de Carajás. In: SBG, Congresso Brasileiro de Geologia, 40, Belo Horizonte, Anais, Resumos, 137.

Oliveira T.F. 1998. As minas de Vazante e de Morro Agudo, Minas Gerais. In: Depósitos Minerais Brasileiros de Metais-Base, Workshop, Extended Abstracts, 48-57.

Palermo N. 1996. Le gisement aurifére Précambrien de Posse (Goiás, Brésil) dans son cadre géologique. L' École Nationale Supérieure de Mines de Paris, Doutorado, 340 $\mathrm{P}$

Pimentel M.M. \& Fuck R.A. 1992. Neoproterozoic crustal accretion in central Brazil. Geology, 20:375-379.

Sato K. 1998. Evolução crustal da Plataforma Sul Americana, com base na geoquímica isotópica $S m-N d$. Inst. de Geociências, Universidade de São Paulo, São Paulo, Tese de Doutoramento, $350 \mathrm{p}$.

Schrank A. \& Machado N. 1996 a. Idades U-Pb em monazitas e zircões das Minas de Morro Velho e Passagem de Mariana - Quadrilátero Ferrífero (MG). In: SBG, Congresso Brasileiro de Geologia, 39, Camboriu, Anais, 6:470-472.

Schrank A. \& Machado N. 1996 b. Idades U-Pb em monazitas e zircões do Distrito Aurífero de Caeté, da mina de Cuiabá e do depósito de Carrapato - Quadrilátero Ferrífero (MG). In: SBG, Congresso Brasileiro de Geologia, 39, Camboriu, Anais, 6:473-475.

Schobbenhaus C. \& Coelho C.E.S. (Eds.), 1986. Principais Depósitos Minerais Brasileiros - Ferro e Metais da Indústria do Aço. DNPM, Vol. 2, 501 p.

Schobbenhaus C. \& Coelho C.E.S. (Eds.), 1988. Principais Depósitos Minerais Brasileiros - Metais Básicos Não Ferrosos, Ouro e Aluminio. DNPM, Vol. 3, 670 p.

Schobbenhaus C. \& Coelho C.E.S. (Eds.), 1992. Principais Depósitos Minerais Brasileiros - Gemas e Pedras Preciosas. DNPM, Vol. 4, 423 p.

Schrank A. \& Machado, N. 1996. Idades U-Pb em monazitas e zircões das Minas de Morro Velho e Passagem de Mariana - Quadrilátero Ferrífero (MG). In: SBG, Congresso Brasileiro de Geologia, 39, Camboriu, Anais, 6:470-472.

Tallarico F.H.B., Rego J.L., Oliveira C.G. 1998a. A mineralização de Au-Cu de Igarapé Bahia: um depósito da classe óxido de Fe (Cu-U-Au-ETR). In: SBG, Congresso Brasileiro de Geologia, 40, Belo Horizonte, Anais, Resumos, 116.

Tallarico F.H.B., Rego J.L., Oliveira C.G. 1998 b. Petrografia e mineralogia da sequência vulcânica encaixante da mineralização de Au-Cu de Igarapé Bahia - Carajás. In: SBG, Congresso Brasileiro de Geologia, 40, Belo Horizonte, Anais, Resumos, 157.

Tazava E., Gomes N.S., Oliveira C.G. 1998. Significado da pirosmalita no depósito de $\mathrm{Cu}-\mathrm{Au}$ (U, ETR) de Igarapé Bahia, Província Mineral de Carajás. In: SBG, Congresso Brasileiro de Geologia, 40, Belo Horizonte, Anais, Resumos, 161. 